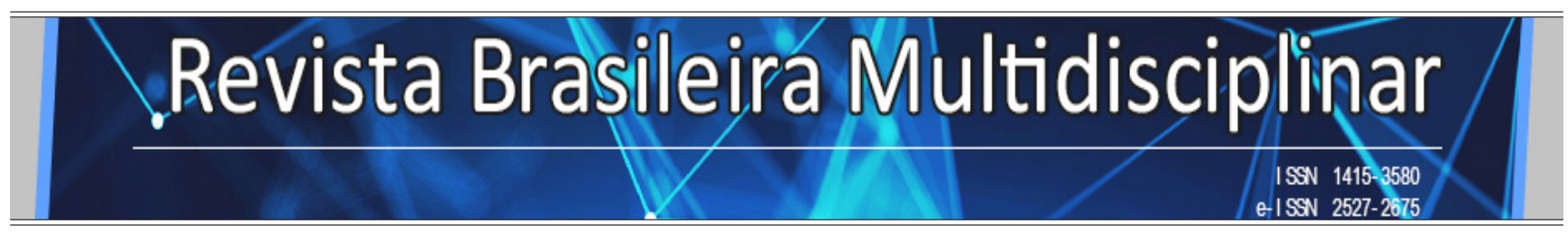

http://revistarebram.com/index.php/revistauniara

\title{
INCENTIVO À GESTÃo AMBIENTAL EM INCUBADORAS DE EMPRESAS: PRÁTICAS E FATORES CONDICIONANTES
}

Mônica Domingues Carvalho*; Sergio Azevedo Fonseca ${ }^{* *}$; Helena Carvalho De Lorenzo ${ }^{* * *}$; Larissa Camerlengo Dias Gomes*; Geralda Cristina de Freitas Ramalheiro ${ }^{\star * * *}$

${ }^{*}$ Mestre em Desenvolvimento Territorial e Meio Ambiente. Universidade de Araraquara.

**Professor Titular da Universidade Estadual Paulista "Julio de Mesquita Filho" - Faculdade de Ciências e Letras.

***Vice-Coordenadora e docente do Programa de Pós Graduação em Desenvolvimento Territorial e Meio Ambiente - Universidade de Araraquara.

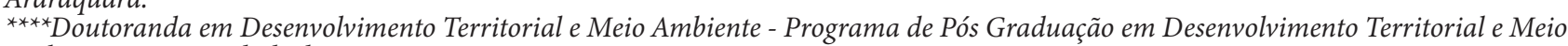
Ambiente - Universidade de Araraquara.

${ }^{*}$ Autor para correspondência e-mail: monicadominguesc@gmail.com

\section{Palavras-chave}

Sistema político

Incubadoras de Empresas

Incentivos e Práticas

\section{KEYWORDS}

Environmental Management

Business Incubators

Incentives and Practices

\section{RESUMO}

Este artigo aborda o potencial das incubadoras de empresas como indutoras de melhorias no desempenho ambiental dos empreendimentos incubados. Foi elaborado com base em pesquisa quantitativa realizada entre os anos de 2015 e 2016 junto à totalidade das incubadoras instaladas no Estado de São Paulo. Os resultados evidenciaram poucas práticas ambientais próativas sendo que o estabelecimento de regulamentos obrigatórios e a aplicação de penalidades decorrentes de infrações a normas internas são as principais práticas de gestão ambiental adotadas pelas incubadoras.

\begin{abstract}
INCENTIVE TO ENVIRONMENTAL MANAGEMENT IN BUSINESS INCUBATORS: PRACTICES AND CONDITIONING FACTORS

This article discusses the potential of business incubators as inducers of improvements in the environmental performance of incubated enterprises. It was elaborated based on a quantitative research carried out between the years of 2015 and 2016 with the totality of the incubators installed in the State of São Paulo. The results evidenced few proactive environmental practices, and the establishment of mandatory regulations and the application of penalties due to infractions to internal norms are the main environmental management practices adopted by the incubators.
\end{abstract}




\section{INTRODUÇÃo}

Este artigo visa a apontar as potencialidades das incubadoras de empresas para a adoção de práticas de indução e implementação de melhorias no desempenho ambiental dos empreendimentos incubados. A gestão ambiental vem ganhando espaço crescente na estratégia de uma vasta gama tipológica de organizações. No universo das incubadoras, contudo, é um tema incipiente. Literatura brasileira recente apontou uma grande escassez de incubadoras com orientação ambiental, no Brasil como em âmbito internacional (FONSECA; MARTINS, 2010; FONSECA; JABBOUR, 2012; FONSECA, 2015; LABIAK JÚNIOR, 2004). Esse descompasso está presente também no arcabouço jurídico. Nota-se que as referências às incubadoras de tecnologias limpas são totalmente inexistentes na legislação brasileira (FONSECA, 2015; FONSECA; MARTINS, 2010).

O caminho para mudanças nesse quadro pode abranger iniciativas como as sugeridas por Fonseca e Jabbour (2012), Fonseca, Souza e Jabbour (2010) e Fonseca (2010). São recomendações que, se implementadas, contribuiriam para a incorporação da dimensão ambiental nas incubadoras e empresas incubadas. Essas recomendações abrangem três esferas, sendo a primeira referente à engenharia e ao espaço físico da incubadora; a segunda está relacionada à seleção dos candidatos à incubação; a terceira compreende as ações de caráter permanente que as incubadoras deveriam realizar com o propósito de melhorar continuamente as condições e os efeitos ambientais das empresas e das suas próprias iniciativas.

Pesquisa realizada ao final da primeira década dos anos 2000 (FONSECA; MARTINS, 2010) revelou que número ainda restrito de incubadoras brasileiras recomendavam que as empresas candidatas não fossem poluentes, limitassem a geração de resíduos e promovessem a educação ambiental e a difusão de técnicas ambientais tanto para os seus empresários quanto para o público externo. Outras medidas apuradas foram a busca pela redução do consumo de energia, pela redução e uso eficiente de insumos e pelo reaproveitamento dos descartes. Por meio dessas informações os autores concluíram que, mesmo com essas iniciativas, a realização de investimentos ambientais pelos empreendimentos assistidos ainda era baixa e, quando ocorriam, tinham motivações muito mais econômicas do que decorrentes da educação ambiental ou devido à consciência da necessidade da adoção de posturas ambientalmente corretas.

Outra constatação da pesquisa foi a de que número expressivo de gerentes de incubadoras defendem "que não é papel da incubadora investir na promoção de estratégias ambientais junto às empresas, ou mesmo na difusão de sistemas de gestão ambiental” (FONSECA; MARTINS, 2010, p.547). Confirmando essa orientação, Labiak Junior (2004) observa que a maioria dos gestores das incubadoras não possuía conhecimento sobre os processos produtivos das empresas incubadas, com o que se viam impedidos de apoiar práticas ambientais tais como a certificação ISO 14001 e a elaboração de planos de emergência ambiental; do mesmo modo, notaram que não existia um acompanhamento efetivo do desempenho das empresas que praticam a gestão ambiental e que não era realizada uma cobrança visando à responsabilidade ambiental das empresas (LABIAK JÚNIOR, 2004).

Exceções, contudo, são observadas. Fonseca (2015) aponta duas incubadoras, uma norte-americana e outra brasileira, que estão inseridas na lógica da economia verde, ponderando os evidentes distanciamentos entre as realidades dos dois países, seja nos números de incubadoras inseridas no campo das tecnologias limpas, seja na mobilização de atores institucionais que atuam no apoio a essas incubadoras. Um dos fatores indicativos para esse distanciamento é a intensidade do envolvimento dos três segmentos institucionais relevantes: enquanto na incubadora norte-americana constatou-se um intenso envolvimento da academia e do Estado, no caso da incubadora brasileira esses dois agentes praticamente se mostram ausentes. Trata-se de constatação que, paradoxalmente, revela uma circunstância oposta ao perfil predominante (em termos dos vínculos institucionais) da extensa maioria das incubadoras de empresas existentes 
no país, ora vinculadas a universidades, ora vinculadas a governos locais, ora vinculadas a instituições sem fins lucrativos, porém mantendo laços de redes com universidades e governos (FONSECA, 2015).

De modo análogo, Hernández e Carrà (2016) observam que o desenvolvimento sustentável é uma dimensão importante para que as incubadoras de empresas sejam capazes de melhorar o desempenho dos empreendimentos assistidos, ao longo de toda a cadeia de valor. Para tanto destacam a importância de se implementar estratégias como a integração e a coordenação na gestão da incubadora, com isso aumentando dependências mútuas e melhorando relações para garantir os recursos necessários. Neste contexto, as relações com organizações parceiras são relevantes para impulsionar o desenvolvimento empresarial sustentável.

O caráter colaborativo e integrador é reafirmado por Costa et al., (2013), apontando que, no cenário nacional, as incubadoras com enfoque ambiental contribuem para melhorar a gestão dos resíduos, promovem benefícios econômicos, sociais e ambientais na medida em que oferecem oportunidades de empregos para a população local e geração de renda a partir da produção de produtos com matéria prima reciclável. Contudo, essas ações são possíveis apenas quando as incubadoras são integradas a outras políticas públicas, quando suas ações se identificam com a comunidade local e quando são assumidas pelos atores.

O caráter de política pública das iniciativas de criação e operação de incubadoras é reafirmado por Fonseca, Souza e Jabbour (2010). Os autores destacam as potencialidades e as possibilidades das incubadoras de empresas fomentarem práticas ambientais nas empresas assistidas. Para tanto, reconhecem a importância da dimensão ambiental como fator de competitividade e assumem, como premissas, as dificuldades históricas e estruturais da pequena empresa de realizar investimentos em dimensões que não a econômica. Em seus resultados fica claro o grande distanciamento das incubadoras brasileiras em relação ao papel que deveriam cumprir como agentes de políticas públicas de promoção do desenvolvimento local sustentável.

Esse distanciamento fica evidente em Cardoso et al. (2008). Ao estudarem uma das mais importantes incubadoras do Brasil, o Centro de Incubação de Empresas de Tecnologia (CIETEC) comprovam que, embora existam preocupações na incubadora quanto à seleção de projetos sócio-ambientalmente adequados, o potencial existente na instituição para fomentar e induzir as empresas incubadas à abordagem do Desenvolvimento Sustentável é pouco explorado. A incubadora pesquisada solicitava o levantamento dos impactos ambientais de produtos e processos na elaboração dos Planos de Negócios elaborados. Além disso, no processo de capacitação a principal atenção da incubadora foi com relação à legislação ambiental e, no processo de avaliação do desempenho, os autores consideraram a conformidade com a legislação ambiental, a geração de resíduos tóxicos e a eficiência na utilização dos recursos.

De modo geral, postula-se que as incubadoras podem adotar diferentes estágios no desempenho ambiental. Fonseca e Jabbour (2012) sugerem a existência de quatro estágios: (1) a fase de 'omissão', em que haveria incubadoras que não levam a gestão ambiental em consideração; a segunda fase é a do 'discurso', isto é, incubadoras que percebem, no discurso, a relevância da gestão; na terceira fase a 'aplicação', as incubadoras adotam a gestão ambiental; por fim, no quarto estágio, 'liderança', incubadoras tomam medidas proativas ambientais em várias dimensões e se tornam referência.

Em síntese, observa-se que a questão ambiental no âmbito das incubadoras de empresas ainda é incipiente. Apesar disso, pode-se considerar que elas oferecem ambientes propícios para a minimização das dificuldades enfrentadas pelas MPEs, contribuindo para a maior adesão de melhores práticas administrativas, incluindo as voltadas à gestão ambiental. Essa relação, entre ambiente e gestão ambiental é retomada em seção posterior deste artigo. 
Partindo dessa contextualização inicial, este artigo relata e discute os resultados de uma pesquisa realizada em 2015, junto a 16 incubadoras de empresas situadas no Estado de São Paulo, pesquisa que buscou avaliar o grau de comprometimento das incubadoras para com o incentivo e a promoção de iniciativas e práticas ambientais pelas empresas incubadas. Para o alcance desse objetivo o artigo foi estruturado em cinco seções, incluída esta introdutória. A segunda seção contempla, referenciada na literatura pertinente, os desafios para a gestão ambiental em incubadoras. A terceira seção aborda a metodologia utilizada na pesquisa, legando à quarta o tratamento dos resultados. Na última seção são apresentadas as considerações finais e as conclusões.

\section{INCUBADORA E GESTÃO AMBIENTAL}

Chamando a atenção desde o início dos anos 2000, o professor Ignacy Sachs (2003) já defendia a necessidade da adoção de instrumentos de políticas públicas que incentivassem as micro e pequenas empresas (com ênfase particular no Brasil) a adotarem práticas capazes de melhorar o seu desempenho ambiental. Entre esses instrumentos têm lugar as incubadoras de empresas, que podem contribuir para atenuar uma das principais dificuldades enfrentadas pelas MPEs, que é o despreparo, o desconhecimento e a falta de experiência e treinamento, tanto do proprietário-dirigente quanto de seus funcionários. Como defendem Parker, Redmond e Simpson (2009), ações para a superação dessas limitações não devem ser aplicadas isoladamente, ademais precisam estar relacionadas ao universo das MPE, se mostrarem convenientes para implementação, aplicáveis, mensuráveis e apresentarem futuras oportunidades aos negócios. Para ilustrar essa condição Demajorovic e Santiago (2011) apontaram que 65\% dos empresários que aplicaram procedimentos voltados à área ambiental só o fizeram devido ao apoio e à disponibilidade de informações fornecidas pelo Programa Sebrae-SP de Gestão Ambiental.

Outra dificuldade, muito mencionada na literatura, e que as incubadoras também podem atuar para amenizá-la, está relacionada à capacidade de financiamento e ao alto custo de implementação e manutenção das práticas de gestão ambiental. A alteração deste contexto de falta de capital pela MPE deve ser um ponto primordial a ser trabalhado em qualquer programa que vise o desenvolvimento da competitividade dessas empresas. Conforme mencionado por Barros (1978, p. 138): “a estreita associação entre a assistência técnica e financeira é indispensável em qualquer programa destinado a estimular o novo espírito da empresa".

As MPEs, além das dificuldades supracitadas, inerentes ao seu ambiente interno, também ficam imunes a pressões e incentivos do ambiente externo, notadamente no que diz respeito à ausência de exigências quanto à melhoria do desempenho ambiental por parte dos clientes, principalmente quando elas operam em mercados baseados em liderança por custos. Tais melhorias, como aponta Labiak Junior (2005), podem representar mais uma oportunidade de atuação para as incubadoras, que podem apoiar as empresas assistidas a explorarem novas oportunidades de negócios que valorizem a preocupação ambiental.

Para atuarem como indutoras dessa mudança de postura, as incubadoras dispõem de instrumentais normativos variados, com destaque para as suas normas internas, como sugerido por Parker, Redmond e Simpson (2009). Tais normas, de acordo com os autores, compreendem editais de seleção, regimentos internos e contratos de adesão a serem seguidos pelos empreendimentos assistidos, nos quais poderiam (e derveriam!) constar critérios, direitos e obrigações de cunho ambiental. As penalidades financeiras, outro tipo de intervenção, também podem ser aplicadas no ambiente de incubação mediante o estabelecimento de punições pelo descumprimento das obrigações ambientais estabelecidas tanto no contrato de adesão quanto no regimento interno.

As auditorias e revisões também se constituem em mecanismos utilizados pelas incubadoras para o acompanhamento e a análise do desempenho das empresas incubadas e que deveriam, além dos critérios 
financeiros, produtivos e de recursos humanos, já utilizados para mensurar o desenvolvimento das empresas, abranger o ambiental. Com base nessas premissas, pode-se sugerir que as incubadoras de empresas sejam ambientes favoráveis à implementação integrada de todas as intervenções propostas por Parker, Redmond e Simpson (2009) e que, além disso, possam contribuir para a minimização de algumas das dificuldades enfrentadas pelas MPEs visando à melhoria do seu desempenho ambiental. A sistematização das dificuldades, oportunidades e possibilidades, elaborada a partir de ampla consulta à literatura, é apresentada no quadro 1.

Quadro 1 - Correlação entre as dificuldades, ações praticadas e intervenções observadas na literatura.

\begin{tabular}{|c|c|c|c|c|}
\hline & Principais dificuldades & $\begin{array}{l}\text { Práticas } \\
\text { sugeridas }\end{array}$ & Intervenções possíveis \\
\hline \multirow{5}{*}{ نَّ } & 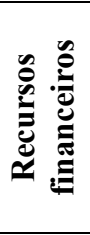 & $\begin{array}{l}\text { Alto custo de implantação; } \\
\text { Alto custo de manutenção; } \\
\text { Falta de capital de giro. }\end{array}$ & $\begin{array}{l}\text { Suporte } \\
\text { financeiro }\end{array}$ & $\begin{array}{l}\text { Indicação de fontes de } \\
\text { financiamento; } \\
\text { Elaboração de projetos; } \\
\text { Identificação de oportunidades } \\
\text { de negócios; } \\
\text { Oferta de capacitação. }\end{array}$ \\
\hline & 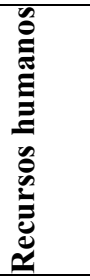 & $\begin{array}{l}\text { Despreparo, } \\
\text { empreendedores e de } \\
\text { trabalhadores; } \\
\text { Falta de treinamento e } \\
\text { acesso à informação; } \\
\text { Falta de consciência } \\
\text { ambiental. }\end{array}$ & $\begin{array}{l}\text { Educação } \\
\text { autodirigida } \\
\text { e facilitada; } \\
\text { Consultoria. }\end{array}$ & Oferta de capacitação. \\
\hline & 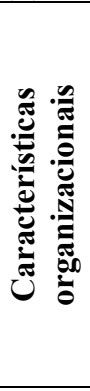 & $\begin{array}{l}\text { Centralização das decisões; } \\
\text { Poucos funcionários, } \\
\text { essencialmente } \\
\text { multifuncionais; } \\
\text { Informalidade dos } \\
\text { processos e da estrutura } \\
\text { organizacional; } \\
\text { Cultura organizacional; } \\
\text { Orientação para o curto } \\
\text { prazo }\end{array}$ & $\begin{array}{l}\text { Educação } \\
\text { autodirigida } \\
\text { e facilitada; } \\
\text { Consultoria } \\
\text { Regulament } \\
\text { os } \\
\text { obrigatórios } \\
\text { e } \\
\text { voluntarios. }\end{array}$ & $\begin{array}{l}\text { Oferta de capacitação; } \\
\text { Penalidades financeiras; } \\
\text { Acompanhamento da empresa. }\end{array}$ \\
\hline & 窇 & $\begin{array}{l}\text { Baixa pressão e não } \\
\text { exigência por parte dos } \\
\text { clientes; } \\
\text { Falta de incentivos } \\
\text { governamentais; } \\
\text { Falta de linhas de } \\
\text { financiamento. }\end{array}$ & $\begin{array}{l}\text { Suporte } \\
\text { financiero; } \\
\text { Penalidades } \\
\text { financeiras. }\end{array}$ & $\begin{array}{l}\text { Identificação de oportunidades } \\
\text { de negócios; } \\
\text { Penalidades financeiras; } \\
\text { Identificação de fontes de } \\
\text { financiamento; } \\
\text { Elaboração de projetos. }\end{array}$ \\
\hline & صٌ & $\begin{array}{l}\text { Burocracia dos órgãos } \\
\text { governamentais; } \\
\text { Excesso de exigências. }\end{array}$ & $\begin{array}{l}\text { Regulament } \\
\text { os } \\
\text { obrigatórios } \\
\text { e } \\
\text { voluntarios; } \\
\text { Auditorias e } \\
\text { revisões. }\end{array}$ & $\begin{array}{l}\text { Estabelecimento de critérios } \\
\text { ambientais para a seleção; } \\
\text { Acompanhamento das empresas } \\
\text { incubadas. }\end{array}$ \\
\hline
\end{tabular}

Fonte: Resultados da pesquisa (2016) adaptado de Iraldo, Testa e Frey (2010); UNEP (2003); HILARRY (2004); TILLEY (1999); ALMEIDA, JABBOUR E REBELATTO (2005); IDROGO (2003); AHORN (2006); CAMPOS (2006); HINZ, VALENTINA, FRANCO (2007); LOPES (2010); FONSECA E MARTINS (2010); RIUL (2010); DEMAJOROVIC E SANTIAGO (2011); FIGUEIREDO (2004); BORGES (2005) e PARKER, REDMOND E SIMPSON (2009). 
Nota-se que as ações relacionadas a incentivos para a melhoria do desempenho ambiental das MPEs devem ter como base o comprometimento e a postura ambiental dos proprietários-dirigentes. O conhecimento das dificuldades associadas à adoção de práticas que objetivam a melhoria do desempenho ambiental das MPEs possibilita a proposição de ações que interfiram positivamente nesse contexto. A pesquisa cujos resultados são adiante relatados buscou confirmar essas proposições, além de verificar se os outros membros da estrutura organizacional e parceiros das incubadoras também exercem influência.

\section{Metodologia}

Esta pesquisa foi realizada em conformidade com as seguintes definições e procedimentos metodológicos: pesquisa quantitativa, com propósitos descritivo e exploratório, delineada como survey, tendo como instrumento único de coleta de dados um questionário enviado por e-mail a gestores das 55 incubadoras de empresas do Estado de São Paulo, dos quais 16 retornaram.

Os dados obtidos permitiram avaliar o Grau Geral de Atitude de Incentivo (GGAI) dos gerentes das incubadoras. O GGAI corresponde a um índice idealizado para esta pesquisa, referenciado, conceitual e metodologicamente, na escala de Likert, aplicado com o propósito de avaliar o grau de comprometimento da incubadora com o incentivo a práticas ambientais junto às empresas incubadas. No total são 29 práticas (quadro 3), organizadas em cinco categorias: práticas estratégicas, práticas de prevenção, práticas educativas, práticas de controle e práticas de controle/prevenção. Tais práticas foram mapeadas na literatura sobre a gestão ambiental em MPEs e em incubadoras de empresas (COSTA et al., 2013; LABIAK JÚNIOR, 2004; PARKER; REDMOND; SIMPSON, 2009; FONSECA; MARTINS, 2010; DEMAJOROVIC; SANTIAGO, 2011; FONSECA; JABBOUR, 2012; ramalheiro et al., 2013; FONSECA, 2015; HERNÁNDEZ; CARRÀ, 2016; RIUL, 2010; FIGUEIREDO, 2004; BORGES, 2005).

A escala do GGAI, variando de um a cinco, possui nos extremos as opções "sempre" e "nunca", acrescidas da opção não aplicável (NA), codificada como zero. A fórmula de cálculo contempla a equação a seguir (Quadro 2):

Quadro 2 - Equação número 1.

\begin{tabular}{|c|c|c|}
\hline \multirow{3}{*}{ GGAI = } & & Sendo: \\
\hline & PT & PT = Pontuação total na escala \\
\hline & $\mathrm{NT}-\sum_{\mathrm{NA}}$ & NA = Alternativa assinalada como "Não aplicável" \\
\hline & & NT = Número total de questões \\
\hline
\end{tabular}

Fonte: Resultados da pesquisa (2016).

Os resultados foram interpretados por meio de uma tipologia atitudinal de cinco níveis:

1- Atitude muito desfavorável: a incubadora não incentiva a implementação de procedimentos de melhoria ambiental.

2 - Atitude desfavorável: existe pela incubadora um incentivo incipiente a implementação de procedimento de melhoria ambiental.

3 - Neutralidade: existe o incentivo às práticas de melhoria ambiental pela incubadora, porém essa não é tão incisiva e nem abrangente com relação as diversas práticas ambientalmente corretas.

4 - Atitude favorável: a incubadora tem uma postura de incentivo mais incisiva e abrangente que a 
citada anteriormente, induzindo seus incubados a implementação das diversas práticas ambientalmente corretas.

5 - Atitude muito favorável: a incubadora tem uma postura de incentivo extremamente incisiva e abrangente, induzindo seus incubados à implementação das diversas práticas ambientalmente corretas.

Além da identificação de atitudes, o questionário buscou mapear as características gerais das incubadoras, tais como ano de fundação, nível de escolaridade de seus gestores, parcerias, principais serviços e infraestrutura oferecidos. Os resultados são relatados na seção que segue.

\section{Resultados}

O primeiro resultado diz respeito à caracterização das incubadoras, com dados sintetizados no Quadro 3.

Quadro 3 - Características gerais das incubadoras.

\begin{tabular}{|c|c|c|c|}
\hline & Tradicional & Mista & Tecnológica \\
\hline Quantidade & Cinco & Sete & Quatro \\
\hline Ano de fundação & $1997-2004$ & $1997-2007$ & $2001-2004$ \\
\hline $\begin{array}{l}\text { Grau de Escola- } \\
\text { ridade do Gestor }\end{array}$ & $\begin{array}{l}\text { Ensino médio e su- } \\
\text { perior }\end{array}$ & Superior & Superior \\
\hline Parceiros & $\begin{array}{l}\text { Prefeitura Municipal } \\
\text { SEBRAE } \\
\text { Universidades } \\
\text { Escolas Técnicas }\end{array}$ & $\begin{array}{l}\text { Prefeitura Municipal } \\
\text { SEBRAE } \\
\text { Universidades } \\
\text { Entidades empresariais }\end{array}$ & $\begin{array}{l}\text { Prefeitura Municipal } \\
\text { SEBRAE } \\
\text { Universidades } \\
\text { Escolas Técnicas } \\
\text { Entidades empresariais }\end{array}$ \\
\hline $\begin{array}{l}\text { Serviços ofere- } \\
\text { cidos }\end{array}$ & $\begin{array}{l}\text { Secretaria; } \\
\text { Orientação empre- } \\
\text { sarial; } \\
\text { Consultorias diversas; } \\
\text { Assessoria Jurídica; } \\
\text { Suporte para proprie- } \\
\text { dade intelectual. }\end{array}$ & $\begin{array}{l}\text { Secretaria; } \\
\text { Orientação Empresarial; } \\
\text { Consultorias diversas; } \\
\text { Assessoria Jurídica; } \\
\text { Apoio para propriedade in- } \\
\text { telectual e para exportação; } \\
\text { Suporte em informática; } \\
\text { Apoio para gestão ambiental; } \\
\text { Laboratórios. }\end{array}$ & $\begin{array}{l}\text { Secretaria; } \\
\text { Orientação Empresarial; } \\
\text { Consultorias diversas; } \\
\text { Assessoria Jurídica; } \\
\text { Apoio para propriedade intelectual e } \\
\text { para exportação; } \\
\text { Suporte em informática; } \\
\text { Apoio para gestão ambiental; } \\
\text { Laboratórios. }\end{array}$ \\
\hline
\end{tabular}


Quadro 3 - Características gerais das incubadoras (cont.).

\begin{tabular}{|c|c|c|c|}
\hline Infraestrutura & $\begin{array}{l}\text { Módulos de uso indi- } \\
\text { vidual; } \\
\text { Secretaria; } \\
\text { Sala de reuniões; } \\
\text { "Show room"; } \\
\text { Sala de serviços de } \\
\text { apoio. }\end{array}$ & $\begin{array}{l}\text { Módulos de uso individual; } \\
\text { Secretaria; } \\
\text { Sala de reuniões; } \\
\text { Sala de treinamento; } \\
\text { "Show room”; } \\
\text { Sala de serviços de apoio. }\end{array}$ & $\begin{array}{l}\text { Módulos de uso individual; } \\
\text { Secretaria; } \\
\text { Sala de reuniões; } \\
\text { Sala de treinamento; } \\
\text { "Show room”; } \\
\text { Sala de serviços de apoio. }\end{array}$ \\
\hline $\begin{array}{l}\text { Condições } \\
\text { observadas no } \\
\text { processo de } \\
\text { seleção }\end{array}$ & $\begin{array}{l}\text { Viabilidade mercado- } \\
\text { lógica; } \\
\text { Potencial de inovação; } \\
\text { Potencial e disposição } \\
\text { para a implementação } \\
\text { de medidas de caráter } \\
\text { ambiental. }\end{array}$ & $\begin{array}{l}\text { Viabilidade econômica e } \\
\text { financeira; } \\
\text { Viabilidade mercadológica; } \\
\text { Potencial de inovação; } \\
\text { Projetos que já possuem al- } \\
\text { gum enfoque ambiental ou } \\
\text { com potencial para adoção } \\
\text { de gestão ambiental. }\end{array}$ & $\begin{array}{l}\text { Viabilidade mercadológica; } \\
\text { Viabilidade técnicas, econômica e } \\
\text { financeira; } \\
\text { Potencial de inovação; } \\
\text { Projetos que já possuem algum enfo- } \\
\text { que ambiental ou com potencial para } \\
\text { adoção da gestão ambiental; } \\
\text { Qualificação dos proponentes; } \\
\text { Disponibilidade de capital; } \\
\text { Potencial de captação de recursos; } \\
\text { Maturidade da equipe. }\end{array}$ \\
\hline
\end{tabular}

Fonte: Resultados da pesquisa (2016).

As informações do quadro permitem algumas inferências preliminares, relativas ao comparativo entre as incubadoras dos três tipos: a) maior flexibilidade quanto ao perfil de formação de gerentes nas incubadoras tradicionais; $b$ ) uniformidade nos perfis das infra-estruturas e das redes de parcerias institucionais externas; c) maior diversidade e complexidade dos serviços internos oferecidos pelas incubadoras mistas e tecnológicas, vis-à-vis as tradicionais; d) progressividade nas exigências e no rigor para a seleção de candidatos à incubação, no percurso entre as incubadoras tradicionais e as tecnológicas. No que diz respeito à temática da gestão ambiental nas incubadoras, o que esse conjunto de dados permitiu apurar é que há uma disposição, aparentemente latente e generalizada, em dar preferência, nos processos de seleção de empreendedores candidatos à incubação, a projetos que já possuam algum enfoque ambiental ou que apresentem potencial para a futura adoção de práticas ou medidas de caráter ambiental. Não foi possível constatar, contudo, se essa preferência se traduz em critérios objetivos e expressos de maior valorização de tais projetos em detrimento dos que ignorem por completo os condicionantes ambientais.

Uma vez concluída a caracterização, aborda-se, na seqüência e como segunda escala de resultados da pesquisa, a distribuição das atitudes das incubadoras em relação à gestão ambiental, com base no índice GGAI. Os dados são apresentados visualmente nas figuras 1 e 2 e no quadro 4. 
Figura 1 - GGAI por incubadora pesquisada.

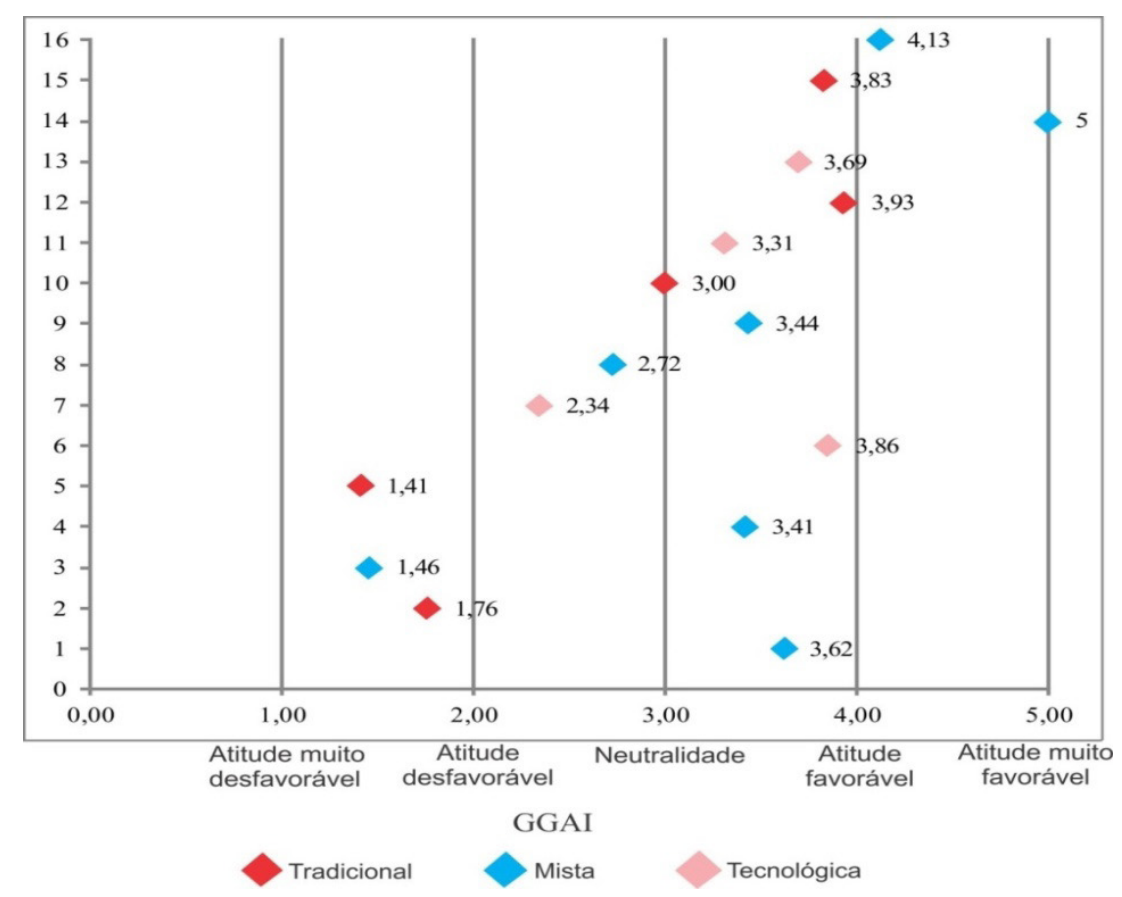

Fonte: resultados da pesquisa (2016).

Os dados do índice GGAI, retratados na figura 1, refletem que: a) a maioria das incubadoras que responderam à pesquisa (62,5\%), aproximadamente $2 / 3$ do total, expressaram opiniões favoráveis à adoção de posturas e atitudes capazes de incentivarem as empresas para a incorporação de medidas e práticas de gestão ambiental; b) apenas três incubadoras, duas tradicionais e uma mista, revelaram posturas claramente distanciadas dessa propensão majoritária; c) há uma maior tendência das incubadoras mistas e tecnológicas ( $v i s-\grave{a}$-vis as tradicionais) para se perfilarem no plano mais próximo ao da indução às práticas ambientais.

Esse perfil, ou essas tendências, podem estar sinalizando uma mudança de postura, uma vez que, conforme apontado por Fonseca e Martins (2010), até o final da primeira década dos anos 2000 o discurso ambiental ainda não havia invadido o ambiente organizacional das incubadoras. Essa maior permeabilidade, constatada na pesquisa por meio da aplicação do índice GGAI, embora seja promissora, ainda deve ser encarada com reservas, uma vez que as iniciativas e medidas mais incentivadas pelas incubadoras são as voltadas à redução do consumo de energia e de água (v. quadro 3), práticas essas que, conquanto possuam um apelo de cunho ambiental, grande parte das vezes têm suas principais motivações ancoradas nas lógicas da economia de custos e dos ganhos produtivos (DEMAJOROVIC; SANTIAGO, 2011; AHORN, 2006).

Detalhando mais os resultados da pesquisa, o quadro 4 registra a totalidade das práticas investigadas pela pesquisa, inspiradas na literatura (RIUL, 2010; AHORN, 2006; LABIAK JÚNIOR, 2004; FONSECA, 2010), pontuando cada qual com seus respectivos índices GGAI e agrupando-as em cinco conjuntos de classes, sistematizadas pela literatura especializada (BARBIERI, 2005; DEMAJOROVIC; SANTIAGO, 2011; AHORN, 2006; SIMONS, 2006). A primeira delas, qualificada como Educativa (ED), abrange 
Quadro 4 - Práticas ambientais incentivadas pelas incubadoras pesquisadas.

\begin{tabular}{|c|c|c|}
\hline Práticas incentivadas & Código & $\begin{array}{l}\text { Média } \\
\text { GGAI }\end{array}$ \\
\hline A discussão sobre questões ambientais? & 1.ED & 3,31 \\
\hline O diálogo entre empresas para melhoria do desempenho ambiental? & 2.ED & 2,80 \\
\hline A redução das emissões de gases poluentes? & 1.CO & 3,77 \\
\hline A coleta seletiva dos resíduos? & 2.CO & 3,93 \\
\hline A reciclagem externa dos resíduos? & 3.CO & 3,64 \\
\hline A disposição correta dos resíduos? & 4.CO & 3,69 \\
\hline A otimização do uso das matérias-primas? & 1.CP & 3,67 \\
\hline A redução do consumo de energia? & 2.CP & 4,14 \\
\hline A redução do consumo de água? & 3.CP & 4,08 \\
\hline O uso de tecnologias limpas no processo produtivo? & 1.PE & 3,64 \\
\hline O uso de matéria-prima menos poluente? & 2.PE & 3,40 \\
\hline O uso de matéria-prima reciclada? & 3.PE & 3,29 \\
\hline O reuso de resíduos no processo produtivo? & 4.PE & 2,79 \\
\hline A reciclagem dos resíduos internamente? & 5.PE & 3,13 \\
\hline A reciclagem de águas usadas? & 6.PE & 2,45 \\
\hline A captação e purificação de águas pluviais para posterior uso na empresa? & 7.PE & 1,78 \\
\hline A revisão dos projetos dos produtos visando menor impacto ambiental? & 8.PE & 3,25 \\
\hline $\begin{array}{l}\text { O levantamento e análise dos impactos ambientais oriundos das atividades das } \\
\text { empresas incubadas? }\end{array}$ & 9.PE & 2,85 \\
\hline $\begin{array}{l}\text { O controle e acompanhamento dos resíduos e efluentes gerados pelas atividades } \\
\text { das empresas incubadas? }\end{array}$ & 10.PE & 2,33 \\
\hline $\begin{array}{l}\text { O controle e acompanhamento para minimização dos impactos ambientais gerados } \\
\text { pelas empresas incubadas? }\end{array}$ & 11.PE & 2,31 \\
\hline A elaboração de planos de emergência ambiental? & 12.PE & 2,18 \\
\hline A adoção de rótulos/selos ambientais? & 1.ES & 2,67 \\
\hline A elaboração de produtos ambientalmente corretos? & 2.ES & 3,53 \\
\hline $\begin{array}{l}\text { A elaboração de produtos/serviços que objetivam melhoria de desempenho } \\
\text { ambiental dos clientes? }\end{array}$ & 3.ES & 3,29 \\
\hline A elaboração de programas de gestão ambiental? & 4.ES & 2,83 \\
\hline A análise do ciclo de vida do produto? & 5.ES & 2,50 \\
\hline A implementação de sistemas de gestão ambiental? & 6.ES & 2,50 \\
\hline Parceria com fornecedores ambientalmente corretos? & 7.ES & 2,79 \\
\hline A certificação ISO 14001? & 8.ES & 2,64 \\
\hline
\end{tabular}

Fonte: Resultados da pesquisa (2016).

ações de sensibilização das pessoas, de promoção de sentidos de co-responsabilidade, de percepção sistêmica da condição de interdisciplinaridade e intersetorialidade dos processos e de entendimento da estreita relação entre qualidade de vida e práticas sustentáveis, no ambiente da empresa e fora dela 
(Simons, 2006). A segunda categoria, qualificada por Barbieri (2005) como de Controle (CO), abrange ações esporádicas, essencialmente de caráter reativo, de cunho corretivo, com o uso de tecnologias en$d$-of-pipe e responsivas à legislação e a pressões da comunidade. O terceiro grupo, qualificado como de Controle e Prevenção (CP), reúne práticas motivadas principalmente pela lógica econômica e objetivam fundamentalmente a eficiência produtiva (DEMAJOROVIC; SANTIAGO, 2011; AHORN, 2006). O quarto grupo, denominado por Barbieri (2005) como de Prevenção (PE), busca alcançar o uso eficiente de insumos, abrangendo ações corretivas e preventivas, de conservação e substituição de insumos e de uso de tecnologias limpas. Finalmente a quinta abordagem, também defendida por Barbieri (2005) e por ele denominada de Estratégica (ES), tem como foco a competitividade, apoiada em visão de médio e longo prazo, na antecipação de problemas e na captura de oportunidades, com o uso de tecnologias limpas e tendo as atividades ambientais disseminadas pela organização e pelas cadeias de suprimentos.

Transpondo-se os dados do quadro a um gráfico radar, no qual foram introduzidos os tipos de incubadoras, é possível visualizar (tal como na figura 2) a distribuição das práticas relacionadas no quadro 3 e suas respectivas importâncias relativas, conforme pontuação pelo GGAI.

Figura 2 - Distribuição das práticas por tipo de incubadora.

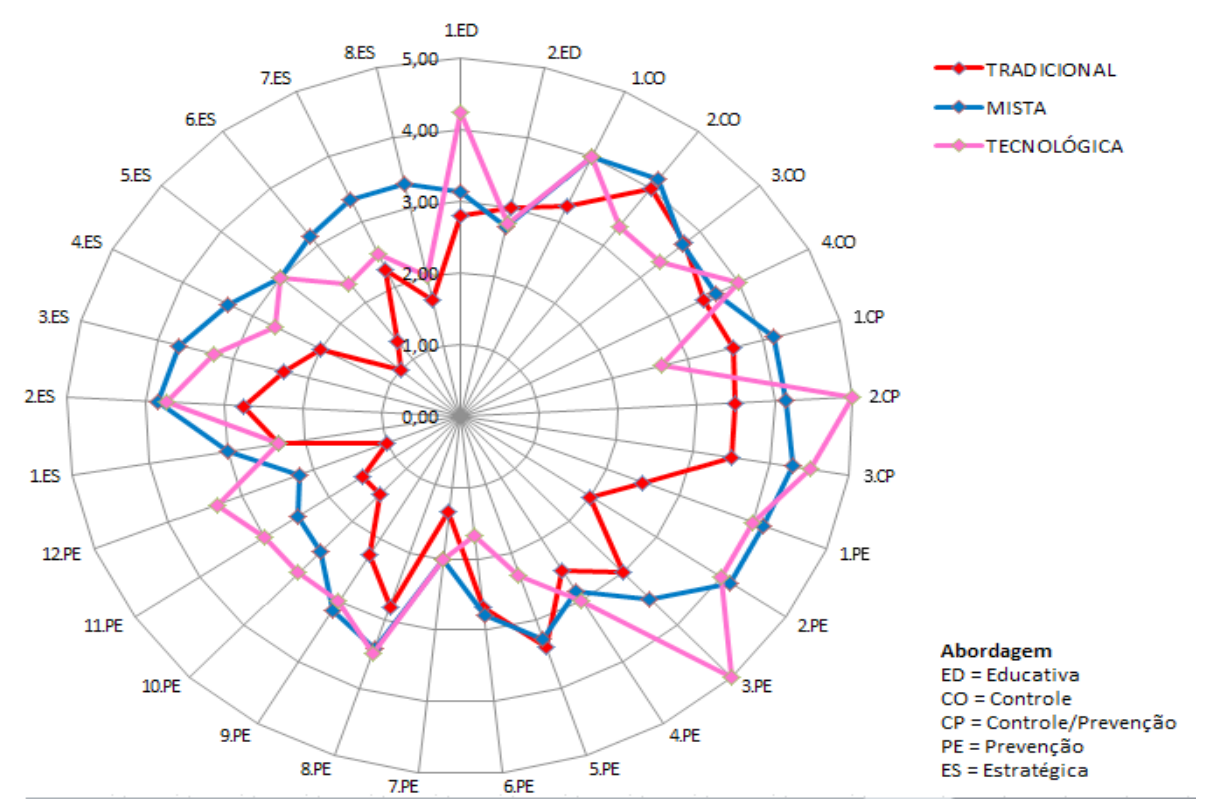

Fonte: Resultados da pesquisa (2016).

A partir da observação da figura é possível constatar que: a) há uma clara supremacia das incubadoras tecnológicas e mistas na promoção de ações de incentivo à adoção de práticas ambientais pelas empresas assistidas, quando comparadas às suas congêneres classificadas como tradicionais; b) contrariando supostas expectativas, tendentes a atribuir às incubadoras tecnológicas um padrão de desempenho ambiental de patamar mais elevado, os resultados da pesquisa, retratados na figura, revelam uma maior propensão das incubadoras mistas à mais alta valorização de práticas qualificadas como estratégicas; c) as práticas que receberam as maiores pontuações no GGAI, notadamente pelas incubadoras tecnológicas e mistas, foram algumas das enquadradas nas categorias de controle e prevenção e de prevenção. As constatações 
"b" e "c", quando interpretadas de forma dialógica, podem conduzir à inferência de que o alcance das iniciativas das incubadoras de cunho ambiental opera essencialmente na esfera "micro", ou seja, dentro das empresas e empreendimentos assistidos pelas incubadoras, deixando de lograr extravasamentos capazes de afetarem de forma virtuosa o ambiente externo, sobretudo no que diz respeito aos mercados e às cadeias de suprimentos com quem as empresas incubadas mantém vínculos. Em outras palavras, as contribuições ambientais das incubadoras, no que diz respeito à inoculação da dimensão ambiental em processos de desenvolvimento local ainda seriam tímidas.

Uma terceira dimensão analítica, propiciada pela pesquisa, é a relativa aos meios e instrumentos utilizados pelas incubadoras com vistas a sensibilizar e estimular as empresas para a adoção de práticas ambientais. Foram identificados quatro tipos de iniciativas (palestras, consultorias, cursos e treinamentos, entre outros menos citados) e onze grandes temas abordados. Os dados são ilustrados na figura 3.

Figura 3 - Temas ambientais abordados como palestras e outras formas de capacitação.

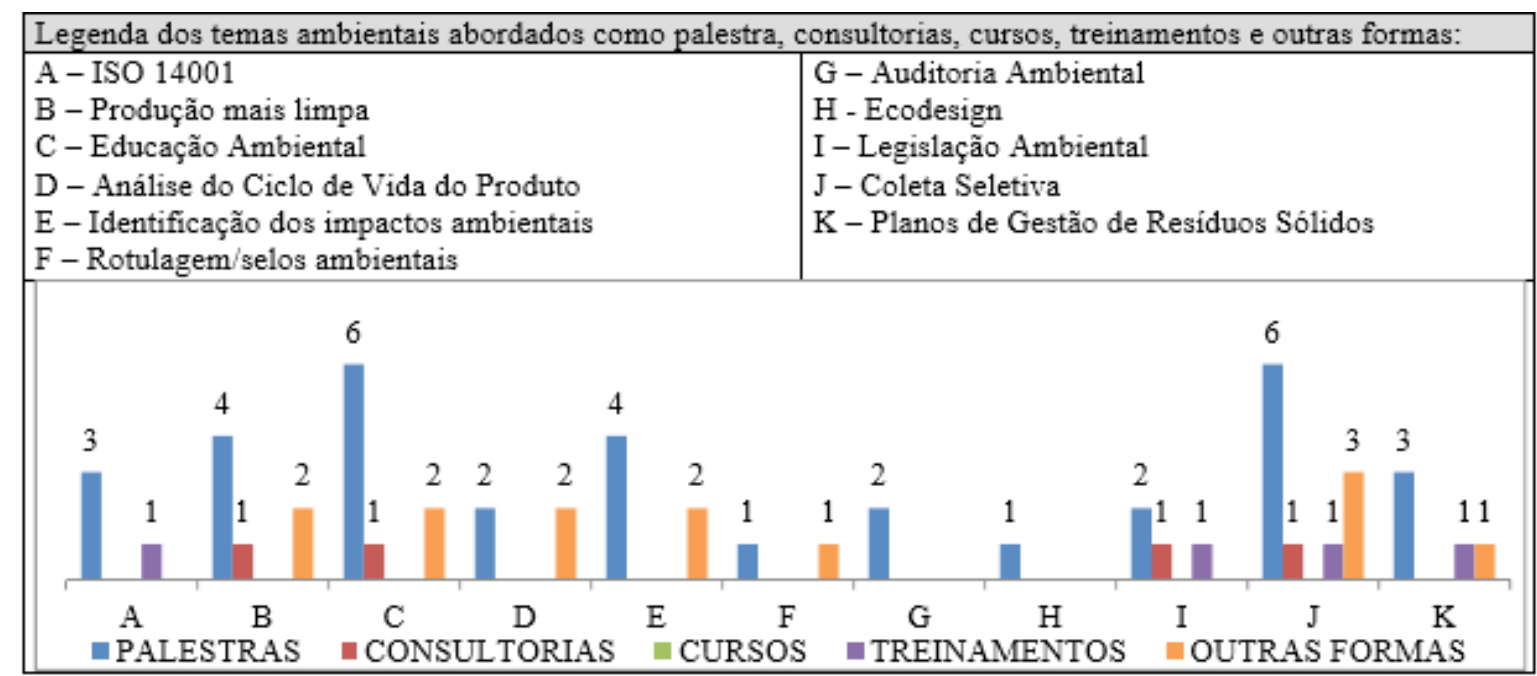

Observação: Os rótulos do gráfico indicam a quantidade de incubadoras que abordaram o referido tema ambiental.

Fonte: Resultados da pesquisa (2016).

Como se observa, a mais freqüente entre as iniciativas, utilizada para o tratamento de todos os temas listados, é a das "palestras". Trata-se da mais fugaz entre as quatro formas de capacitação mais citadas na pesquisa e aquela que, segundo Carvalho (2011), está orientada para uma rápida, grande parte das vezes superficial, transmissão de conhecimentos e informações (quando não de mera sensibilização) tendo, segundo o mesmo autor, como uma de suas desvantagens, limitações para possibilitar o estabelecimento de correlações entre os conteúdos transmitidos e as potenciais aplicações dos mesmos nas realidades particulares dos destinatários participantes dos eventos - representantes das empresas incubadas.

Já no que diz respeito aos temas abordados, tiveram amplo destaque os de educação ambiental e coleta seletiva, ou seja, temas amplos e genéricos, sem que haja evidências, ao menos pelos dados fornecidos pela pesquisa, do estabelecimento de correlações diretas com questões relativas à gestão ambiental, próprias de ambientes de micro e pequenas empresas.

\section{CONSIDERAÇões FINAIS}


A pesquisa realizada, conquanto marcadamente exploratória - seja pelo ineditismo, reconhece-se, um tanto ousado, do índice utilizado, seja pela limitação da amostra, ou seja, ainda, pelo estágio ainda bastante incipiente do conhecimento em torno do tema abordado - possibilitou inferir algumas conclusões, a partir dos resultados obtidos. A primeira, mais evidente e abrangente de todas, corrobora com a literatura quanto à baixa importância atribuída às considerações de caráter ambiental pelas incubadoras pesquisadas, sobretudo diante das dimensões econômica e de inovação.

Uma segunda constatação, também passível de ser tratada como conclusiva, é de caráter metodológico. Sugere-se aqui que o índice utilizado para apurar a propensão ao desempenho ambiental de incubadoras, o GGAI, possa ser reconhecido como válido para o alcance dos seus propósitos e aplicável (ou seja, passível de extrapolações), embora merecendo aprimoramentos futuros.

No tocante às iniciativas constatadas pela pesquisa, de parte das incubadoras, para a promoção de práticas ambientais, seja pelas incubadoras enquanto unidades organizacionais, seja pelos empreendimentos abrigados, o que se pode concluir é que, além da timidez das mesmas, encontram-se distantes dos horizontes estratégicos das incubadoras e afastadas de seus processos de planejamento. Evidências maiores que sustentam essa conclusão são a ausência de explícitos critérios ambientais nos processos de seleção de empreendimentos candidatos à incubação, a inexistência, generalizada, de condicionantes ambientais nos projetos estruturais das incubadoras e o vazio de processos sistêmicos, multidimensionais, integrados e permanentes, orientados para a progressiva melhoria do desempenho ambiental, dos empreendimentos assistidos e da incubadora como um todo.

Para finalizar, deve-se dar destaque a uma outra importante contribuição da pesquisa, que não pode ser menosprezada ou minimizada, possuindo cunho mais propriamente praxiológico, ou seja, correspondendo ao caráter indicativo para mudanças de posturas e comportamentos de gestores de incubadoras, tendentes a propiciarem aprimoramentos na gestão ambiental das mesmas, inclusive com o apontamento das práticas mais fragilizadas e das mais promissoras.

\section{REFERÊNCIAS}

AHORN, M. R. A dimensão socioambiental das pequenas empresas no contexto da terceirização: fragilidades e alternativas. Dissertação (Mestrado em Gestão Integrada em Saúde e Meio Ambiente). Centro Universitário Senac - Santo Amaro, São Paulo, 2006.

ALMEIDA, M. R.; JABBOUR, C. J. C.; REBELATTO, D. A. N. Considerações sobre a interiorização da dimensão ambiental em uma pequena empresa agroindustrial. In: SIMPÓSIO INTERNACIONAL EM GESTÃO AMBIENTAL, SAÚDE E SEGURANÇA DO TRABALHO. Anais..., 2005, São Paulo - SP.

BARBIERI, J. C. Technological Base Business Parks and Incubators. São Paulo, 2005.

BARROS, F. R. de. Pequena e Média Empresa e Política Econômica: Um desafio à mudança. Rio de Janeiro: APEC, 1978.

BORGES, M. S. Sustentabilidade ambiental nas pequenas empresas: implementação interativa de produção mais limpa (p+l). Estudo de uma empresa metalmecânica do ramo automotivo. Dissertação (Mestrado em Engenharia Civil). Universidade Estadual de Campinas - Unicamp, Campinas, 2005. 
CAMPOS, L. M. S. Sistemas de Gestão Ambiental para Pequenas Empresas: uma comparação entre as visões das grandes empresas certificadas, dos implementadores e das pequenas empresas. ENEO. Anais... ENEO, 2006.

CARDOSO, A. C. F. et al. Incubadoras orientadas para o desenvolvimento sustentável: é possível? O caso do Centro de Incubação de Empresas de Tecnologia (Cietec). Revista de Gestão Social e Ambiental, v. 2, n. 2, p. 69-87, 2008.

COSTA, I. M. A importância das incubadoras com enfoque ambiental na Gestão de Resíduos Sólidos Urbanos: o caso da INCUBALIX/ES. Anais...Altec: 2013.

DEMAJOROVIC, J.; SANTIAGO, A. L. F. Responsabilidade socioambiental na micro e pequena empresa: práticas e desafios. Gestão.Org. Revista Eletrônica de Gestão Organizacional, n. 9. v. 2, pp. 254 - 281 , maio/ago. 2011.

FIGUEIREDO, V. F. Produção mais limpa nas pequenas e micro empresas:elementos inibidores. ENCONTRO NAC. DE ENG. DE PRODUÇÃO., 24 . Anais... Florianópolis, SC, Brasil, 03 a 05 de nov de 2004.

FONSECA, S. A. Modelo para a avaliação do desempenho e o apoio à gestão de incubadoras. 2010. Universidade Estadual Paulista (UNESP), Araraquara, 2010

FONSECA, S. A. Incubadoras como vetores para a promoção de tecnologias limpas em empreendimentos de pequeno porte: possibilidades e limites. RAM. Revista de Administração Mackenzie, v.16, n.1, p.188-212, 2015.

FONSECA, S. A.; JABBOUR, C. J. C. Assessment of business incubators' green performance: A framework and its application to Brazilian cases. Technovation, v.32, n.2, p.122-132, 2012.

FONSECA, S. A.; MARTINS, P. S. Gestão ambiental: uma súplica do planeta, um desafio para políticas públicas, incubadoras e pequenas empresas. Produção, v.20, n.4, 2010.

FONSECA, S. A.; SOUZA, S. B.; JABBOUR, C. J. C. Desafios e oportunidades das incubadoras de empresas para a incorporação de estratégias ambientais. O\&S, v.17, n.53, p.331-344, 2010.

HERNÁNDEZ, R.; CARRÀ, G. A Conceptual Approach for Business Incubator Interdependencies and Sustainable Development. Agriculture and Agricultural Science Procedia, v.8, p.718-724, 2016.

HINZ, R. T. P.; VALENTINA, L. V. D.; FRANCO, A. C. (2007). Monitorando o desempenho ambiental das organizações através da produção mais limpa ou pela avaliação do ciclo de vida. Revista Produção online, v.7, n.3, 2007.

IDROGO, A. A. C. Sistema Integrado de Gestão da Qualidade, Meio Ambiente e Saúde e Segurança no Trabalho - um modelo para a pequena empresa. Tese (Doutorado em Engenharia da Produção). 
Universidade Federal de Santa Catarina - UFSC, Florianópolis, 2003.

IRALDO, F.; TESTA, F.; FREY, M. Environmental Management System and SMEs: EU Experience, Barriers and Perspectives. Source: Environmental Management, Book edited by: Santosh Kumar Sarkar, 2010. 258 p.

LABIAK JÚNIOR, S. Habitat's para um empreendedorismo sustentável: estudo de ferramentas para potencializar práticas inovativas. 2004. Centro Federal de Educação Tecnológica do Paraná, 2004.

LOPES, J; R; N. Desafios e alternativas para a gestão ambiental em pequenas empresas: uma análise do programa de qualificação de fornecedores da FIEB. Dissertação (Mestrado em Engenharia Ambiental e Urbana). Universidade Federal da Bahia, Salvador, 2010.

PARKER, C; M.; REDMOND, J.; SIMPSON, M. A Review of Interventions to Encourage SMEs to Make Environmental Improvements. Environment and Planning C: Government and Policy, v.27, n.2, p.279_ 301, 2009.

RATINHO, T.; HENRIQUES, E. The role of science parks and business incubators in converging countries: Evidence from Portugal. Technovation, v.30, n.4, p.278-290, 2010.

RIUL, M. Diagnóstico e diretrizes para a gestão de aspectos sociais e ambientais no APL de móveis de João Pessoa - PB. Dissertação (Mestrado em Desenvolvimento e Meio Ambiente). Universidade Federal da Paraíba. João Pessoa-PB. 2010.

SACKS, E; W. Community Foundations Global Status Report 2003. WINGS - Worldwide Initiatives for Grantmaker Support, 2003

SIMONS, M; O. Educação ambiental na empresa: mudando uma cultura. In: VILELA JUNIOR, A.; DEMOJOROVIC, J. (Orgs). Modelos e ferramentas de gestão ambiental: desafios e perspectivas para as organizações. São Paulo: Editora Senac, p. 199-218, 2006.

TILLEY, F. Small-Firm Environmental Strategy: The UK Experience. Greenleaf Publishing Ltd., 1999. UNEP. Small and médium-sized enterprises and sustainability: facts na figures. UNEP Industryand Environment, 2003. 